\title{
O Transe como Performance no Candomblé e Umbanda
}

Bruno Karasiaki Filene ${ }^{\mathrm{a}}$ Gabriel Omar Alvarez ${ }^{\mathrm{b}}$

\begin{abstract}
Resumo: No artigo compreendemos o transe enquanto performance de mediação da tradição cultural. Apresentamos o transe como modo performático em contraste com outras abordagens que trabalham o transe como conceito. Esta abordagem permite compreender o transe no ritual como manifestação das noções de pessoa nas religiões de matriz africana e afrobrasileira. $O$ estado de transe faz parte das tradições e se expressa em um espaço liminar ritual. Espera-se que Orisàs e entidades sejam performados pelos iniciados no espaço público.
\end{abstract}

Palavras-chave: Transe, Candomblé, Umbanda, Etnografia, Performances Culturais.

As performances culturais do transe são elementos constitutivos das religiões afro-brasileiras, dos candomblés, macumbas e umbandas. Essas religiões, tanto de matriz africana na América Latina, de matriz afro-brasileira ou afro-indígenas, possuem elementos comuns, nas performances de transe. Via de regra o transe emerge enquanto incorporação das representações coletivas reconhecidas entre as tradições religiosas.

a Mestrando no Programa de Pós-graduação Interdisciplinar em Performances Culturais (UFG). Email: brunofilene@discente.ufg.br.

b Professor do Programa de Pós-Graduação em Antropologia Social (PPGASUFG). Email: gabriel.o.alvarez@gmail.com. 
O transe como modalidade performática apresenta variações específicas. Nas performances de incorporação/encorporação, podemos refleti-lo teoricamente a partir do paradigma da performance (Bauman 1975; Bauman \& Briggs 2003; Turner 1988; Langdon 2006 e 2016) jogando uma nova luz sobre este processo social que não foi devidamente explorado entre os precedentes que tentaram explicá-lo. Nos candomblés, a incorporação do transe ocorre nas performances dos Orixás. Na umbanda, são incorporadas entidades pertencentes a falanges, internas às sete linhas de umbanda. Existem diversas umbandas, porém a prática do transe mediúnico é elemento comum. Enquanto os orixás se expressam pela dança, nas entidades da umbanda prevalece a palavra. 'Entidade que não fuma não fala'.

Os campos para reflexão do transe na umbanda foram algumas casas de diversificados regimentos em Goiânia, onde ocorrem semanalmente rituais com consulta às entidades, além de 'passes' e 'transferências'. Para pensar o candomblé, utilizamos além de parte da bibliografia clássica do tema, que fundamenta o debate do transe no Brasil, diversas experiências de campo realizadas em mais de uma casa de candomblé de Goiânia-GO e Salvador-BA, em situações etnográficas diferentes pelos autores.

Há diversas abordagens acerca do tema transe. A etimologia da palavra remete ao latim transire (trans- através + -ire - ir) isto é, 'ir além de'. Sua utilização e sentido também indicam outras formas simbólicas das ciências médicas. Também remete ao 'êxtase místico' performado culturalmente em contextos tradicionais. A palavra aponta para a ideia de trânsito e transitoriedade. Em nossa conceituação é um estado liminar em que a pessoa é tomada pela performance da entidade ou orixá. Esta performance questiona o eu racional, consciente, que durante a performance permite lugar à expressão de um 'eu não consciente', a pessoa é o orixá e seu corpo é o meio de expressão deste, e das entidades. $\mathrm{O}$ transe como performance é um símbolo tradicional compartilhado por candomblés e umbandas. 
O transe foi abordado a partir de diversos paradigmas nas ciências sociais. Os primeiros estudos, centrados na alteração do estado consciente, tentaram explicá-lo a partir de hipóteses médicas centradas no indivíduo. Uma segunda geração de estudos antropológicos deslocou o eixo do indivíduo para a sociedade, e focalizou o mesmo como um africanismo transnacionalizado. Nosso interesse, ao olhar o transe a partir do conceito teórico de performances é ressaltar seu caráter de fenômeno coletivo, expressado a partir dos corpos que participam de uma experiência em relevo (Jakobson 1960 apud Langdon 2006:167), o comportamento intensificado pela performance nas quais se espera que aconteçam estes estados de engajamento corporal, emocional e sensorial.

\section{As explicações do transe}

Um dos primeiros pensadores brasileiros a trabalhar o tema do transe, cuja proposta analítica é tão notória quanto etnocêntrica, foi Nina Rodrigues $(1900,2005)$. Suas análises enraizadas ao escopo biomédico perduram até os dias atuais enquanto marcadores argumentativos, inclusive disseminados pela mídia de massa, que visam legitimar a subalternização das religiões afro-brasileiras, de matriz africana no Brasil e africanas no Brasil.

O autor possui papel central na estruturação do campo médico no Brasil, e é conhecido por ser um primeiro estudioso do Candomblé baiano. Apesar do pioneirismo, Nina Rodrigues prepondera uma argumentação demasiado apegada às ciências médicas, apelando para a psicologia e biologia. Ogã do terreiro Engenho Velho da Casa Branca, o autor via em sua etnografia do candomblé, o estudo da África no Brasil. Ao tentar explicar a experiência etnográfica a partir dos paradigmas da época, o autor recorreu à hipnose, estados alterados do eu pelo uso de substâncias, e à psicopatologia via esquizofrenia, para tentar uma explicação que julgava "científica”, nos moldes do positivismo. 
Entre 1896-1897, Nina Rodrigues publicou uma série de quatro artigos na Revista Brazileira em francês. Intitulados "L' animisme fétichiste dês nègres de Bahia", a coletânea se tornou seu segundo livro quando a obra foi traduzida e organizada por Arthur Ramos (1903-1949) em 1935, também médico legista, discípulo de Nina Rodrigues. O transe é descrito como moléstia mental e associado à teoria da degenerescência. Em 1900, Nina Rodrigues descreve a possessão como "estado de sonambulismo provocado, com desdobramento e substituição de personalidade" (Nina Rodrigues 1900:81 apud Goldman 1985:25).

Arthur Ramos (1935), inspirado pelas teorias de Lévy-Bruhl (1857-1939), e da psicanálise, forjou conceituação do transe de modo mais independente "do reducionismo organicista e dos anátemas da teoria degeneracionista” (Duarte 2005:196). Ramos embora discípulo de Nina Rodrigues, já buscava alternativas analíticas sobre o transe que escapassem da rigidez psiquiátrica, estudando as fronteiras entre o transe e distúrbios psicológicos (Duarte 2005:195). Essa abordagem estaticamente psicológica, perdura mal aplicada em alguns casos até os dias atuais, embora haja produções menos etnocêntricas posteriores às de Nina Rodrigues e Arthur Ramos. Há diferenciações que emergem nas conceituações cunhadas em campo, nos contextos de candomblés e umbandas, entre transe e possessão. Estas devem ser valorizadas tanto quanto os conceitos da psicopatologia em suas conjunturas funcionais. $\mathrm{O}$ transe consiste num estado mais laborioso de se atingir, e remete ao êxtase místico, enquanto a possessão é descrita como fenômeno pulsional, involuntário, nem sempre desejável.

O transe tensiona a noção de pessoa na tradição ocidental (Goldman 1984, 1985 e 1996). Questiona-se com essa divisão da 'noção de pessoa', a 'unidade do eu'. Para Mauss ([1938]2003) a noção de pessoa se apresenta como uma categoria do espírito humano, podendo se manifestar de forma diferente em diversas tradições. Goldman analisa a noção de pessoa, de Eu, na tradição ocidental como uma categoria do pensamento antropológico. Nesse percurso aborda a noção de pessoa em tradições indígenas e orientais. Os dados da pesquisa 
indicam que a noção de pessoa nos cultos afro-brasileiros se assenta na dicotomia entre 'virantes' e 'não virantes', isto é, aqueles que podem virar cavalo do santo e aqueles que cuidam e acompanham estes processos. Goldman (1985:37) sobre a construção ritual da pessoa no candomblé, explicita que o transe embora estimado pelos neófitos, é evitado pelos mais velhos, ao passar das obrigações de axé, o iniciado assenta os santos (orixás) e entidades, materializando assim o carrêgo, externalizando-o. O cumprimento destas obrigações, que organizam a hierarquia do Egbè (comunidade/família espiritual), induz aqueles com maior experiência e obrigações pagas a uma maior resistência ao transe.

Idealmente com a ampliação da experiência e tempo de iniciação espera-se que cada vez menos o transe ocorra, e em intensidades menores. $\mathrm{O}$ transe tanto é estimado quanto evitado, e sua ocorrência deve ser negociada situacionalmente, sendo permitida sua manifestação ideal a partir do nascimento do orixá, isto é, a iniciação. $\mathrm{Na}$ umbanda o transe é manifesto após o desenvolvimento nas sete linhas de trabalho, iniciado nos rituais de 'deitadas'.

O transe, pode ser conceituado como uma complexa forma de comunicação, que pode implicar diálogo, como uma consulta na umbanda, mediada pela psicofonia, seguida de 'transferência' ou 'passe', ou outras formas de comunicação como dança, saudações, gestos e interações. $\mathrm{O}$ mesmo tem que ser compreendido no plano das performances do ritual. Em todos os casos as performances acontecem num período liminal, e envolvem símbolos rituais que instigam a ação (Turner, [1967]2005).

A dialética entre sujeito e sociedade, e as distintas personas que a pessoa assume em determinadas situações, pode ser associada à complexidade da noção de pessoa e suas distintas manifestações estéticas, exegéticas e performáticas na vida cotidiana (Mauss [1938]2003; Goffman 1985). O primeiro a observar a relação entre a noção de pessoa e o fenômeno do transe foi Roger Bastide (2001, 2016). Na abordagem de Bastide, que traz influências durkheimnianas, o social é recortado 
como um campo diferente do psicológico, sendo o segundo centrado no indivíduo (Bastide [1972]2016:287). O autor diferencia em 'O Sonho, o Transe e a Loucura' (Bastide [1972]2016), o transe africano e o transe ocidental, que os demais autores como Nina Rodrigues e Arthur Ramos descrevem sob a ótica das ciências médicas. $O$ transe místico do candomblé, se assemelha com o transe africano, que opera na conformação da estrutura social, e é 'controlado', com a finalidade de "mobilizar massas camponesas para construção de estradas", instituir "mudança nas técnicas agrícolas" etc. Sendo assim, "instrumento de desenvolvimento econômico e social" (Bastide [1972]2016:149). O 'transe ocidental', que não se trata do 'transe místico africano' e afrobrasileiro, é entendido em Bastide como:

"[...] uma forma de protesto ou de contestação do mundo das regras, das normas, e dos valores. Ele é revolta contra a sociedade. A política não ocupa o segundo lugar, mas o primeiro" (Bastide 2016:149).

Consideremos a observação de que no transe ritual afrobrasileiro, o self do indivíduo e a interação social atribuem significado via interação. O significado é produto da interação que comporta fricção simbólica. O transe emerge como modalidade performativa. Não é algo estático, ou pré-definido, trata-se de um processo de construção do sentido. Essa dinamicidade é elemento-chave dos processos de significação. Os processos de comunicação devem valorizar a produção de sentido emergente, ou incorreriam no risco de desconsiderar partes definitivas dos processos comunicativos: a dialética e a dialogia. Os debates na pragmática da Escola de Chicago, fundaram a psicologia social, em curso ministrado por George Herbert Mead (1863-1931). Seu sucessor Herbert Blumer (1900-1987), conceitua o pensamento de Mead, assim como de outros pensadores da escola, a partir do Interacionismo Simbólico (1931); abordagem revista e propalada por estudiosos da comunicação, psicólogos, linguistas, antropólogos, sociólogos e pedagogos.

Os processos de comunicação performativa na umbanda entre espíritos, cuja representação é ideal; e 'consulentes', que por meio 
dos médiuns fazem suas confissões, pedidos e aconselhamentos, direcionando-se para as subjetividades mais elevadas espiritualmente, que 'cavalgam sobre o corpo' do performer (médium); se dão de maneira relativa a elementos nem sempre constantes. A estética, ambientação, o humor geral, as condições climáticas, os pequenos eventos dentro do ritual - tudo - servirá de índice que definirá as performances culturais. Em outras palavras, as disposições preditivas das performances, de como serão, têm no limite do rigor, a compreensão das representações coletivas a serem performadas. No caso da umbanda, as sete linhas de trabalho e suas falanges oferecem essa função referencial. Quanto ao candomblé, Pierre Verger (2000) dedica seu terceiro capítulo sobre a iniciação e o transe. Neste fragmento que segue, pondera que para ocorrer o transe dentro dos parâmetros ideais buscados, é necessário que a pessoa seja iniciada:

"A iniciação consiste em criar no noviço, em determinadas circunstâncias, uma segunda personalidade, um desdobramento mítico inconsciente, durante o qual ele manifestará o comportamento tradicional do Orisa, ancestral divinizado [...]" (Verger 2000:82).

Nina Rodrigues e Arthur Ramos, delimitaram certo espaço teórico para discussão do transe, visto naquele momento como patologia, como prova da suposta 'inferioridade intelectual' do povo negro, resultado da 'histeria' ou da 'dependência de drogas'. A partir dos anos 40, uma mudança epistemológica alcança a discussão. Por influência durkheimniana, os autores passam a pensar o transe como um fato social, como aponta Goldman (1985:26).

Os trabalhos de Bastide $(2001,2016)$ introduziram essa perspectiva durkheimiana, ao analisar o candomblé como religião que reflete a sociedade afro-brasileira. $\mathrm{O}$ sistema de festas e o culto organizam o tempo do terreiro. O espaço do terreiro reúne de forma sintética os diferentes orixás e os elementos da natureza por eles representados. Trata-se de um sistema classificatório complexo que relaciona os orixás com suas características; como forças da natureza, suas cores, suas comidas favoritas, os cantos e toques para convocar os orixás, assim 
como a dança; o xirè. Cada Orixá possui danças próprias, seu raio de atuação, características, especialidades e domínios.

Consideremos também a contribuição do americano Herskovits (1941 apud Almeida, Oda \& Dalgalarrondo 2007:38) que inspira a conceituação de Bastide (2016:148). Herskovits inspirado em Pavlov (1849-1936), trata o fenômeno do transe enquanto "reflexo condicionado" pela introdução da cultura no indivíduo (Almeida, Oda \& Dalgalarrondo 2007:38). Nessa leitura são reproduzidos estímulos ao indivíduo que estando apto a interpretá-los tradicionalmente, torna-se capaz de desenvolver uma 'reação correspondente', interpretada culturalmente 'de fora' pelos espectadores. Desde sempre o transe esteve associado aos fenômenos de comunicação, embora os primeiros pesquisadores tivessem focado mais na narrativa eugenista, devido à proximidade paradigmática com o positivismo. $\mathrm{O}$ transe místico ocorre dentro de um action set delimitado e 'leis gerais' não contemplam sua liminaridade.

O transe condensa mensagens, saberes e fazeres, sendo portanto, ferramenta da transmissão cultural. Os mitos e ritos são duas caras da mesma moeda. Ambos são preservados ao decorrer dos anos nas tradições, e transmitidos em complexos processos comunicativos. Pensando o transe à luz das performances, evidenciamos que assim como elas (as performances), o transe pode se voltar para um público, sendo em alguns casos esse o aspecto central. Ele comunica, permitindo-nos ler o fenômeno do transe enquanto performance cultural, mediadora de comunicação interna às religiões.

Austin (1962) ${ }^{1}$ analisa os aspectos performativos do discurso, seus efeitos ilocucionários, de 'como fazemos coisas com palavras', como no caso dos rituais. Isto é, quando as palavras são pronunciadas pela pessoa apropriada no contexto apropriado, adquirem eficácia simbólica. Um exemplo dado é o ritual de casamento cristão, embora o mesmo se observe em rituais de outras religiões com suas particularidades. Podemos perceber no caso da umbanda, a disposição de uma atmosfera ritual que estimula a licença poética para expressão do 
transcendental, por meio de um alter-ego, que se manifesta, seguindo os parâmetros de uma tradição cultural, na qual esse comportamento não só é possível como esperado. A experiência em relevo modifica o transeunte, os espectadores e outras pessoas em transe.

Bauman (1975), que vem do campo da história oral, chamou atenção para fatores estéticos e poéticos envolvidos nas performances dos narradores. Entre estes fatores, o autor assinala cinco aspectos da performance que balizaram sua análise: o Display, isto é, a exibição de um comportamento frente aos outros; a responsabilidade e competência exibida pelos atores; a avaliação por parte do público; a experiência em relevo, isto é, qualidades expressivas, emotivas e sensoriais que constituem a experiência emergente; e finalmente os keying, marcadores de meta-comunicação que indicam o fim de uma performance.

Turner (1988) ao analisar as performances assinala como aspectos relevantes; seu caráter de processo, o resultado indeterminado das performances as diferenciam de outros rituais pré-estruturados. Enfatiza que a performance envolve vontade, valores e afetos. Em contraste com o homem enquanto animal racional da civilização greco-romana, o autor apresenta o homo performáticus. Nas performances a reflexão é plural e acontece no contexto de uma tradição cultural que inclui uma cosmologia, dotada de eficácia inerente, e relações simbólicas com outras tradições. Nas performances de transe as tradições são atuadas, avaliadas e continuamente sujeitas a revisão. Subjaz uma experiência coletiva, a ser plasmada em performances. Trata-se da corporificação da cultura, seus mitos e processos.

Langdon (2006) ao comparar as abordagens de Bauman e de Turner assinala cinco pontos em comum: Por um lado a Experiência em relevo, esse comportamento intensificado pelos rituais e performances. Assinala que a participação em performances é uma participação expectante, interação na qual o significado emerge do contexto. Não se trata nem de uma ação normativa, nem de uma leitura semântica dos símbolos. As performances envolvem experiências multissenso- 
riais. Diversos estímulos criam uma experiência emotiva, expressiva e sensorial. A autora destaca o envolvimento corporal, sensorial e emocional: A 'encorporação'; grafia semelhante à usada por Shechner (2014), além de alguns comentadores de Csordas (1990) que discorre acerca do 'paradigma da corporificação'. A performance de incorporação não é racional, ela se manifesta nos corpos e com isso rechaça divisão cartesiana da experiência que separa o racional, o emocional e o corporal. Finalmente o significado emergente implica uma experiência imediata, em relevo, e estética.

Nas performances os personagens não atuam como indivíduos, atuam como membros de uma classe, em nome de valores do grupo, como uma tradição encorpada, sejam orixás ou entidades. Durante a performance são mobilizados diversos símbolos que nos falam de uma tradição que os banha de sentido. O significado não se resolve em símbolos isolados, ou colocados em contexto. $\mathrm{O}$ significado emerge na realização da performance. É na performance como processo que estão os significados. Leia-se a performance enquanto experiência vivida, quiças Erlebnis (Dilthey 1914 apud Rodrigues 1991:183).

\section{Transe no candomblé e na umbanda:}

No candomblé os Orixás como símbolos rituais, orientam as performances do transe, enquanto na umbanda há maior espaço para individuação na performance do médium que recebe a entidade. Estas entidades na umbanda são performadas a partir do espírito de uma pessoa ancestral. Um espírito incorporado por meio de uma entidade e corrente espiritual. Nem todo candomblescista é suscetível ao transe místico. Como assinalamos, existem 'virantes' e 'não virantes', no caso dos homens - Ogãs, e no caso das mulheres Ekedjis/Ajoiés. Esses cargos dentro da comunidade são importantes na estruturação do terreiro, cuidando de questões organizacionais da casa, e de segurança da mesma. Na umbanda existem representações coletivas matriciais, embora frequentemente surjam novas linhas, ou reapareçam representações há muito tempo esquecidas. Mesmo que isso ocorra, os espíritos, 
são adaptados e agrupados a uma das sete linhas de umbanda. Nos termos umbandistas, esses espíritos são 'doutrinados'. Dentro dessas linhas existem diversas falanges de erês, caboclos, exus, pretos velhos e índios, conforme podemos verificar na sincrética, vasta e diversificada literatura umbandista. Nas casas de umbanda também existem cargos de 'não virantes' que são os cambones; médiuns de irradiação e dirigentes que podem virar ou não, a depender da necessidade imbuída no trabalho em realização.

No que se refere a diferença do transe nos candomblés e nas umbandas, podemos dicotomizar a partir das representações coletivas cultuadas em cada caso, que são diferentes. Devemos considerar que o proposto elemento da maior 'liberdade performativa' na umbanda seja justificado por se tratar de representações que remetem ao corpo social.

No aspecto cosmológico, isto é operacional comum às tradições, consideremos que as sete linhas de umbanda, em suas exegeses, indicam que as entidades internas a tais linhas de trabalho, estão associadas a algum orixá por meio de sua falange (Rivas Neto 2007:165 apud Brito 2017:54). Existe também nas umbandas, o tratamento de espíritos desencarnados, que não são associados a nenhuma das 'falanges', 'linhas de trabalho', 'sete linhas de umbanda' ou linhas de atuação performativa. Nesse que é o caso de algumas umbandas cruzadas com kardecismo, os nomes dos vivos são registrados em um livro, e em outro livro, 'dos desencarnados', são assinaladas a passagem dos mortos, que não pertencem a nenhuma das linhas. Esse tipo de rito é mais frequentemente praticado em sessões de psicografia, onde os consulentes solicitam às correntes e entidades que mediem o contato com seus entes que partiram ao plano espiritual.

O sincretismo fica evidente nessa altura da análise. As sete linhas são regidas por orixás, que também são sincretizados na umbanda popular com santos católicos. Existem, entretanto, casas com regimentos próprios. Muitas casas de umbanda não possuem como sacerdote uma pessoa iniciada no culto aos orixás. Esse fator pode gerar tensões entre umbandas e candomblés, pois na ontologia candomblecista, a pessoa 
tem que passar por um processo de iniciação e cumprir uma série de obrigações de um, três e sete anos, e por fim, receber um 'Decà', que consiste num balaio com diversos objetos mágicos, só então recebendo outorga para controlarem os eguns (espíritos desencarnados). Essa informação em alguns terreiros é segredo, sendo tratada com maior naturalidade em outros.

Num momento do óró (lê-se orô), como numa 'matança' do candomblé, o transe místico ocorre com intensidade. No exato instante em que o sangue do bicho (Ejè) toca Onilè (a terra), os orixás se manifestam coletivamente. É um momento intenso que precede diversos ritos e está ligado à consagração do alimento. Nesse momento os sacerdotes, Ogãs e Ekedjis/Ajoiés, auxiliam os iniciados que recebem a força dos orixás incorporando, a retornarem às suas personas cotidianas. No candomblé há ritos secretos para iniciados que precedem os rituais públicos, e ritos posteriores, também para já iniciados, sendo o 'transe público' apenas um tipo de performance cultural de matriz africana no Brasil e afro-brasileira.

As performances destas religiões acontecem em seus espaços e públicos, e envolvem uma parte restrita aos iniciados, além de outra parte aberta ao público em geral. Quanto às diferenças relacionadas às relações entre orixás e entidades, há diversos organogramas que circulam na literatura umbandista e acadêmica sobre as sete linhas de irradiação e suas falanges internas (Brito 2017:53). Não é exatamente nosso propósito neste trabalho apontar para aspectos descritivos dessas linhas de atuação performativa, mas é importante frisar certos pontos de articulação entre as linhas de trabalho da umbanda e suas referências simbólicas aos orixás. Referência generalizada nas umbandas, expressa na ideia de que orixás regem as diferentes linhas. A linha de marujos, piratas, sereias e pescadores pertence às linhas de trabalho dos orixás das águas, enquanto os caboclos, caboclas, índios e índias, pertencem ao povo da floresta, e assim sucessivamente. Esse silogismo pode ser encontrado, senão em todos, na maioria dos terreiros, sendo essa relatividade simbólica um fato social que engloba umbandas e candomblés. 
Acerca da 'Construção ritual da pessoa', de Goldman (1984, 1985), o autor traça um caminho pela produção precedente sobre a construção do transe no iniciado, contemplando a necessidade de ainda mais minucioso estudo desse aspecto temático de nossa parte. O campo da antropologia do transe colabora para discussões e descobertas interdisciplinares. As teorias precedentes sobre o tema do transe são muitas, e veiculamos aqui apenas parte pertinente à reflexão sobre o transe como performance cultural em contextos tradicionais e religiosos, embora os performativos inerentes às representações sejam estendidos à vida cotidiana na complexa sociedade brasileira e latino-americana.

As linhas de trabalho da Umbanda, subdivididas em falanges (Sarraceni 2015), são o corpus simbólico que oferece as funções referenciais para mediação comunicativa feita via transe na cultura, entre entidade incorporada e consulentes. No Candomblé, tais mediações se consolidam na relação com os orixás, os arquétipos elementares associados à natureza, e a estrutura social do grupo étnico. $\mathrm{O}$ transe neste último caso, é o veículo mediador entre a comunidade e o orixá divinizado no corpo do iniciado, que pela via ritual comunica à plateia seu novo status na comunidade. As falanges umbandistas, como dissemos, estão ligadas direta e indiretamente às representações dos orixás, tratando-se, portanto, do transe, uma prática comum e inerente ao 'povo de terreiro'.

\section{Considerações finais}

Ao trabalhar o transe como performance deslocamos o eixo do conceito abstrato, para compreendê-lo como um modo performático, uma experiência em relevo que tem lugar em eventos religiosos que acontecem no espaço público do barracão e em outras instâncias rituais reservadas para os iniciados. Tanto os participantes como o público acreditam na presença do orixá ou da entidade que se manifesta durante estes estados de transe, e avaliam a eficácia da performance. 
Estas performances em transe acontecem no período liminar de complexos rituais, marcados no início e no final, realizados por alguém com autoridade e conhecimento para a execução do ritual. Durante o estado de transe o corpo é tomado, atuado pelo orixá ou entidade. Sua performance e o conhecimento do pessoal da casa, permite-nos reconhecer o personagem, qual orixá, no candomblé, ou entidade na umbanda.

O ritual, como complexa forma de comunicação envolve música, comidas, cantos, danças, estados alterados de consciência, num elaborado aparelho multimídia, que inclui os elementos estéticos. Os orixás e entidades são poderosas criaturas que tem seus gostos, sensibilidades e formas de comunicação. Cabe ao pai e mãe de santo orientar o pessoal da casa no cuidado destas entidades que visitam ilè (casa de santo) e se encontram nos assentamentos. Para os participantes do Ilè são espaços sagrados assim como o Barracão. São portais que permitem que as entidades e orixás se expressem nos corpos das pessoas em transe, que durante este período deixam o corpo ser levado pelo orixá, ou pela entidade, num estado sem consciência do eu ocidental, no qual se expressam performaticamente estes seres extraordinários. A performance durante o ritual e a festa cria uma consciência emergente, uma comunicação que pode incluir a palavra, como nas entidades de umbanda, ou bênçãos, danças e dádivas no caso dos orixás.

Existe um amplo leque nas religiões de matrizes africanas, que abarcam candomblés Ketu, Jêjê, Congo, Angola, Efon, Ijexá, assim como variantes regionais como Batuques no Sul, Catimbós no Norte e Xangôs em Recife. Há também amplo leque das religiões afro-brasileiras que abrange diversas umbandas, desde aquelas mais africanizadas à outras mais influenciadas pelo kardecismo e cristianismo. Neste leque podem ser incluídas também as quimbandas que trabalham com diversas entidades de exús, diferentes do Exú Orixá (Ėșù Imolé), cultuado no candomblé e pela religião tradicional africana, Ifá. Esta variabilidade tem que ser entendida nas transformações destas matrizes africanas, nas diversas práticas rituais em tempos e espaços, como 
seus consequentes sincretismos. Apesar desta grande variabilidade, estas religiões têm em comum as performances do transe como forma de comunicação direta com estes seres extraordinários e suas funções referenciais compartilhadas. Dotados de eficácia simbólica, movimento, capacidade equânime de transmissão cultural e mediação comunicativa interna às culturas.

Fotos de transe do candomblé, e dos catiços.

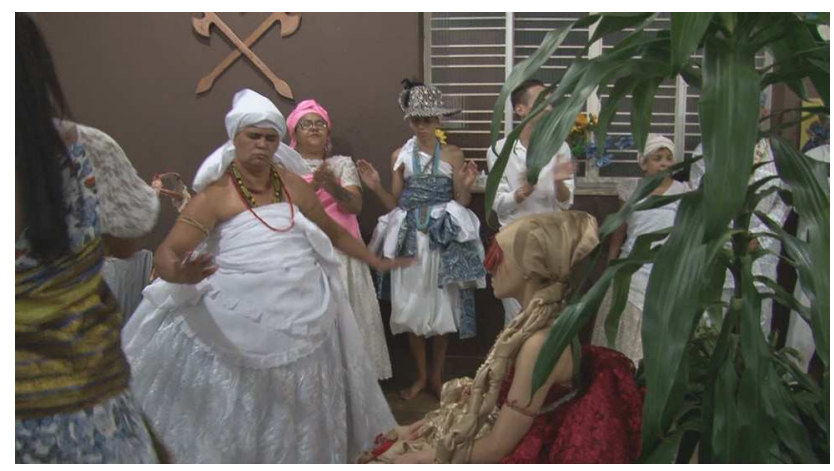

Figura - 1: Carmem de Oyà cumprindo Odu Età, Yago de Odé em saída de Iawo, e Dáfne de Ewa contemplando Odu Ijè. Fotos tiradas no Ilè Asè Dán Fè Erò Ósumarè - Goiânia, GO. Por Bruno K. Filene.

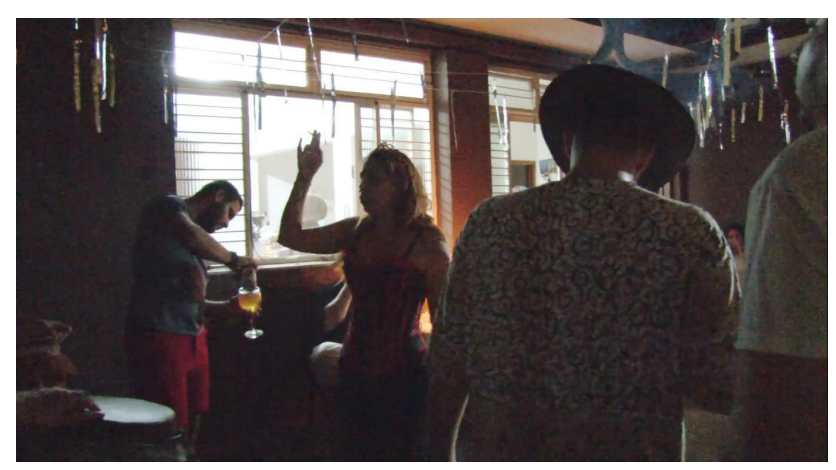

Figura - 2: Maria Padilha incorporada pela Iyalorisà Marilèia de Osúmàré, Trancaruas de costas e cambone à esquerda. Foto por Bruno K. Filene. 


\section{Nota:}

1 John Langshaw Austin (1911-1960) foi um filósofo da linguagem, filiado da Filosofía Analítica, que em seu livro 'Quando Dizer é Fazer' (1962) aponta já no primeiro capítulo elementos classificatórios para os Atos Performativos (Performative Acts), e seus requisitos de eficácia, ou em seus termos; de 'felicidade'.

\section{Referências:}

ALMEIDA, A., ODA, A. M. \& DALGALARRONDO, P. 2007. "O olhar dos psiquiatras brasileiros sobre os fenômenos de transe e possessão". Revista de Psiquiatria Clínica, 34(1):34-41.

ALVAREZ, Gabriel. 2017. "Antropología visual, performances y hermenéutica: experiencia de ver, escuchar y participar en Huautla de Jimenez (Oaxaca, México)". In Baez Landa, M. \& ALVAREZ, G. (eds.): Olhar in(com)formado: teorias e práticas na antropologia visual, pp. 145-194. Goiânia: Editora da Imprensa Universitaria.

. 2020. "Abuela Julieta. Xamanismo contemporâneo em Huautla". Revista Anthropológicas, 31(1):278-307.

AUSTIN, John L. 1990. Quando dizer é fazer. Porto Alegre: Artes Médicas.

BASTIDE, Roger. 2001. O candomblé da Bahia. São Paulo: Companhia das Letras. . [1972]2016. O Sonho, o Transe e a Loucura. São Paulo: Três Estrelas.

BAUMAN, Richard. 1975. "Verbal Art as Performance". American Anthropology, 77(2):290-311.

BAUMAN, R. \& BRIGGS, C. 2003. Voices of Modernity: Language Ideologies and the Politics of Inequality. New York: Cambridge Univerisity Press.

2006. "Poética e Performace como perspectiva crítica sobre a Linguagem e a vida social". Itha, Revista de Antropologia, 8(2):185-229.

BRITO, Lucas G. 2017. 'O véu do congá do pai Joaquim': cosmovisão, ritual e experiência ou sobre três aspectos do conhecimento umbandista. Dissertação de Mestrado. Goiânia: Universidade Federal de Goiás.

CAMARGO, Robson C. 2013. "Milton Singer e as Performances Culturais: Um conceito interdisciplinar e uma metodologia de análise". Revista Karpa, 6(2):01-27.

CARNEIRO, Edison. 2008. Candomblés da Bahia. São Paulo: Martins Fontes.

CSORDAS, Thomas J. 1990. "Embodiment as a Paradigm for Anthropology". Ethos, 18(1):5-47.

DUARTE, Luiz Fernando. 2015. "Os Grandes Problemas da Antropologia Brasileira”. Mana, 21(1):195-212. 
DURKHEIM, Émile. 1989. As formas elementares da vida religiosa: o sistema totêmico na Austrália. São Paulo: Paulinas.

GEERTZ, Clifford. [1973]2003. La interpretación de las culturas. Barcelona: Gedisa. GOFFMAN, Ervin. 1985. A representação do eu na vida cotidiana. Petrópolis: Vozes.

GOLDMAN, Márcio. 1985. "A construção ritual da pessoa: a possessão no candomblé”. Religião e Sociedade, 12(1):22-54.

. 2003. "Os tambores dos mortos e os tambores dos vivos. Etnografia, antropologia e política em Ilhéus, Bahia”. Revista de Antropologia, 46(2):423444.

1996. "Uma categoria do pensamento antropológico: a noção de Pessoa". Revista de Antropologia, 39(1):83-109.

LANDES, Ruth. 2002. A Cidade das Mulheres. 2a ed. rev. Rio de Janeiro: Editora UFRJ.

LANGDON, Esther J. 2016. "The performance of diversity: shamanism as a performative mode". GIS, 1(1):9-39.

. 2006. "Performance e sua Diversidade como Paradigma Analítico:

A Contribuição da Abordagem de Bauman e Briggs". Ilha Revista de Antropologia, 8(1-2):162-183.

MAUSS, Marcel. [1938]2003. "Uma categoria do espírito humano: a noção de pessoa e a de 'eu'”. In Sociologia e Antropologia, pp. 369-397). São Paulo: Cosacnaify.

RODRIGUES, Raimundo N. 1900. L'Animisme Fétichiste des Négres. Salvador: Reis $\&$ Comp. . 2005. O animismo fetichista dos negros baianos. Salvador: Editora P555.

RODRIGUES, Herbert. 2005. "Dewey, Dilthey e Drama: um ensaio em Antropologia da Experiência (primeira parte), de Victor Turner”. Cadernos ee Campo, 13(13):177-185.

SANTOS, Juana E. 1990. Os Nagô e a Morte. Petrópolis: Vozes.

SARRACENI, Rubens. 2015. As Sete Linhas de Umbanda: A Religião dos Mistérios. São Paulo: Madras.

SCHECHNER, Richard. 2014. "'Pontos de Contato' revisitados”. Revista de Antropologia, 56(2):23-66.

TURNER, Victor. [1967]2005. Floresta de Símbolos: Aspectos do Ritual Ndembu. Niterói: EdUFF. . [1969]1974. O Processo Ritual: estrutura e anti-estrutura. Petrópolis: Vozes. . 1988. The Anthropology of performance. New York: Paj Publ.,

VERGER, Pierre. 1992. Fluxo e refluxo do tráfico de escravos entre o golfo de Benin e a Bahia de Todos os Santos: dos séculos XVII a XIX. Salvador: Corrupio.

2019. Notas sobre o culto aos orixás e voduns na Bahia de Todos os Santos, no Brasil, e na antiga Costa dos Escravos, na África. São Paulo: EDUSP. 
VERGER, Pierre. 1987. Orixás. Salvador: Corrupio. . 2000. Notas sobre o culto aos Orixás e Voduns. São Paulo: EDUSP.

\title{
Trance as Performance in Candomblé and Umbanda
}

\begin{abstract}
In the article we understand the trance as a mediation performance of the cultural tradition. We present trance as a performance mode in contrast to other approaches that work with trance as a concept. This approach makes it possible to understand the trance in the ritual as a manifestation of the notions of person in religions of African and AfroBrazilian origin. Traditions include in a preliminary ritual space: Orixás and entities, which in their contexts are performed by initiates in the public religious space.
\end{abstract}

Keywords: Trance, Candomblé, Umbanda, Ethnography, Cultural Performances.

Recebido em abril de 2021. Aprovado em outubro de 2021. 